\title{
Basal and GnRH-induced secretion of FSH and LH in anestrous versus ovariectomized bitches
}

\author{
N.J. Beijerink ${ }^{\text {a,* }}$, J.J.C.W.M. Buijtels ${ }^{\text {a }}$, A.C. Okkens ${ }^{\text {a }}$, \\ H.S. Kooistra ${ }^{a}$, S.J. Dieleman ${ }^{b}$

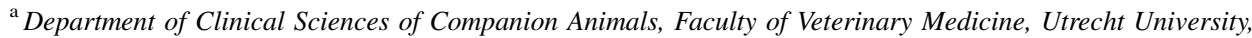 \\ Yalelaan 108, P.O. Box 80154, NL-3508 TD Utrecht, The Netherlands \\ ${ }^{\mathrm{b}}$ Department of Farm Animal Health, Section of Reproduction, Faculty of Veterinary Medicine, \\ Utrecht University, Utrecht, The Netherlands
}

Received 23 December 2005; received in revised form 12 December 2006; accepted 30 December 2006

\begin{abstract}
The basal and gonadotropin releasing hormone ( $\mathrm{GnRH})$-induced plasma concentrations of follicle stimulating hormone (FSH) and luteinizing hormone ( $\mathrm{LH})$ were studied in four anestrous and four ovariectomized (OVX) bitches. Blood samples were obtained via jugular venipuncture $40 \mathrm{~min}$ before and 0, 10, 20, 30, 60, 90, and $120 \mathrm{~min}$ after the i.v. administration of synthetic GnRH in a dose of $10 \mu \mathrm{g} / \mathrm{kg}$ body weight.

The basal plasma FSH and LH concentrations were significantly higher in the OVX bitches than in the anestrous bitches. In the anestrous bitches, the plasma FSH concentration was significantly higher than the pretreatment level at 10, 20, and 30 min, whereas the plasma LH concentration was significantly elevated at 10 and $20 \mathrm{~min}$. The maximal GnRH-induced plasma FSH concentration in the anestrous bitches did not surpass the lowest plasma FSH concentration in the OVX bitches, whereas the GnRH-induced plasma LH concentrations in the anestrous bitches overlapped with the basal plasma LH concentrations in the OVX bitches. In the OVX bitches, GnRH administration did not induce a significant change in the plasma FSH concentration, whereas the plasma LH concentration increased significantly at 10 and $20 \mathrm{~min}$.

In conclusion, the results of the present study indicate that in anestrous bitches GnRH challenge results in increased plasma levels of both FSH and LH, whereas in the OVX bitches, in which the basal plasma FSH and LH concentrations are higher, only a rise in the plasma LH concentration is present after GnRH stimulation. The results also suggest that a test to measure plasma concentration of FSH in single samples appears to have potential in verification of neuter status in bitches.
\end{abstract}

(C) 2007 Elsevier Inc. All rights reserved.

Keywords: Dog; Gonadotropins; Immunoassay; Neuter status

\section{Introduction}

The reproductive cycle of the bitch is under endocrine control exerted by interactions among the hypothalamus, anterior pituitary, and ovary - the so-

\footnotetext{
* Corresponding author. Tel.: +31 302531624; fax: +31 302518126.

E-mail address: N.J.Beijerink@vet.uu.nl (N.J. Beijerink).
}

called hypothalamic-pituitary-ovarian axis. The neuroendocrinological mechanisms responsible for the release of follicle stimulating hormone (FSH) and luteinizing hormone (LH) by the pituitary are very complex. It is generally accepted that these gonadotropins are secreted in a pulsatile fashion [1] in response to the similarly pulsatile release of gonadotropin releasing hormone $(\mathrm{GnRH})$. The gonadotropins stimulate ovarian hormone secretion, which in turn regulates 
the gonadotropins via a negative feedback mechanism (long-loop negative feedback). The extent of $\mathrm{GnRH}$ release and subsequently gonadotropin release seems to be dependent upon sensitivity of the hypothalamus to estradiol. During progression of anestrus, there is gradual reestablishment of positive feedback of estradiol on the hypothalamus [2], and GnRH secretion [3] and the responsiveness of the pituitary to GnRH increase [4]. In addition, a large amount of LH is released prior to ovulation, due to this positive feedback elicited by the rapidly rising plasma estradiol level [5]. Apart from the feedback of the gonadal hormones, two additional feedback loops have been identified. These are the gonadotropin-dependent inhibition of $\mathrm{GnRH}$ production (short-loop negative feedback) and the GnRH-dependent inhibition of GnRH production, known as ultrashort-loop negative feedback [6].

The measurement of plasma FSH and LH concentrations before and after administration of a $\mathrm{GnRH}$ analogue during different reproductive conditions, such as during anestrus and after ovariectomy, permits assessment of the capacity of the pituitary to secrete gonadotropins. Knowledge about the characteristics of gonadotropin secretion after intravenous administration of a $\mathrm{GnRH}$ analogue in the anestrous bitch is mainly limited to $\mathrm{LH}$ [7], the response of which is dosage-dependent [4,8]. Furthermore, an increasing dosage-dependent response of LH to stimulation with GnRH was found in the bitch during the progression of anestrus [4], but another study revealed no apparent correlation between stage of anestrus and LH response [9]. However, the used GnRH dosage in the latter study was minimal. Only one study was concerned with the concomitant secretion of the gonadotropins in the bitch after GnRH administration and showed that in cyclic bitches FSH and LH levels increased within 15 min after GnRH stimulation [10].

Ovariectomy (OVX) influences the long-loop feedback. The loss of inhibitory influence of ovarian steroids and peptides on the hypothalamic-pituitary axis causes a rapid increase in the plasma concentration of both $\mathrm{LH}$ [7,11-16] and FSH [12,13,16], while there are indications that the secretion pattern of both remains pulsatile [13]. Little is known about the characteristics of gonadotropin secretory response to exogenous GnRH in the OVX bitch. Both a rise [7,11] and an unpredictable response [14] in the plasma LH concentration have been reported. So far, in OVX bitches there is no information either on GnRH-induced FSH secretion or on the concomitant secretion of FSH and LH after GnRH administration.

The present study was designed to compare the basal and GnRH-induced plasma concentrations of
FSH and LH in OVX bitches with those in anestrous bitches.

\section{Materials and methods}

\subsection{Animals, treatment, and collection of blood samples}

Four intact Beagle bitches (weighing 11.3-14.1 kg and aged 2-5 years), in which the previous estrous cycle had been monitored and characterized, and four OVX Beagle bitches (weighing 12.8-16.0 kg and aged 9-10 years) were included in this study. All dogs were whelped and raised in the Department of Clinical Sciences of Companion Animals and were accustomed to the laboratory environment and procedures, such as the collection of blood samples. They were housed in pairs in indoor-outdoor runs, fed a standard commercial dog food once daily, and provided with water ad libitum. The four intact Beagles were examined three times per week for the presence of swelling of the vulva and a serosanguinous vaginal discharge, which were considered to signify the onset of proestrus. Plasma concentrations of progesterone were determined three times per week from the start of proestrus until the day on which the plasma progesterone concentration exceeded $16 \mathrm{nmol} / \mathrm{L}$, which is when ovulation was assumed to occur [17-19]. During this study, all bitches were in anestrus (104-118 days after ovulation), as confirmed by plasma progesterone concentrations below $3 \mathrm{nmol} / \mathrm{L}$ [20]. The four remaining dogs had been ovariectomized at the Department of Clinical Sciences of Companion Animals at Utrecht University at least 1 year before the start of the experiment and had exhibited no signs of recurrent estrus.

At $09.00 \mathrm{~h}$ (time is $0 \mathrm{~min}$ ) $10 \mu \mathrm{g} / \mathrm{kg}$ synthetic $\mathrm{GnRH}$ (Fertagyl ${ }^{\mathbb{R}}$ batch 20105B; Intervet International BV, Boxmeer, The Netherlands) was administered via the cephalic vein in all Beagle bitches. Blood samples were taken $40 \mathrm{~min}$ before and $0,10,20,30,60,90$, and 120 min after the administration of $\mathrm{GnRH}$.

Blood samples were collected from the jugular vein, immediately placed in chilled EDTA-coated tubes, and centrifuged at $4{ }^{\circ} \mathrm{C}$ for $10 \mathrm{~min}$ at $1500 \times \mathrm{g}$. Plasma was stored at $-25{ }^{\circ} \mathrm{C}$ until analysis. All samples from each dog were measured in the same FSH or LH assay.

\subsection{Hormone immunoassays and validation of FSH assay}

Plasma FSH concentration was measured by the canine immunoradiometric assay (IRMA) of Biocode 
SA (Liège, Belgium) coded AHCOO4. This IRMA uses a first and a second monoclonal mouse anti-FSH antibody. These antibodies were raised against rat-FSH and have cross-species reactivity (rat, dog, and horse) (personal communication, Biocode SA). Briefly, the procedure used highly purified canine FSH diluted in horse serum provided by the manufacturer to produce a standard curve ranging from 1.5 to $240 \mu \mathrm{g} / \mathrm{L}$. An excess of a first monoclonal mouse anti-rat FSH antibody bound to polystyrene tubes captured the canine FSH present in $100 \mu \mathrm{L}$ standards or samples. Thereafter, a second $\left[{ }^{125} \mathrm{I}\right]$-labeled monoclonal mouse anti-rat FSH antibody $(50 \mu \mathrm{L})$, directed to another determinant on the FSH molecule, was added to the tubes, which were incubated at room temperature for $90 \mathrm{~min}$. According to the manufacturer, the cFSH used as standard was derived from extracts of pituitary glands of dogs collected over several years in Belgium. Pituitary extracts were purified by ion exchange and gel filtration. The monoclonal antibodies were obtained by injecting highly purified rat FSH in mice after which splenocytes of the mice were fused with $\mathrm{Sp} 2 \mathrm{O}$ myeloma cells. Finally, diluted positive clones were tested for binding to iodinated cFSH to obtain highly stabilized monoclonal cells. The reported purity of the antibodies (IgG class) is $>95 \%$. More detailed information on the reagents is not available.

To validate the FSH IRMA for parallelism, accuracy, and precision, plasma from an OVX bitch 10 min after the administration of $10 \mu \mathrm{g} / \mathrm{kg} \mathrm{GnRH}$ was diluted with plasma from an anestrous bitch before GnRH stimulation (dilutions 1:2 to 1:32). Each level of dilution was measured six times. As shown in Table 1, the precision and accuracy are within commonly accepted ranges. In addition, the intra-assay coefficient of variation (CV) was measured in 12 replicates of each of four samples in a single assay. These four quality controls samples were included in duplicate in all assays $(n=12)$ to determine the interassay $\mathrm{CV}$. The intra-assay and the interassay $\mathrm{CV}$ for values above $1.60 \mu \mathrm{g} / \mathrm{L}$ were 3.5 and $15.1 \%$, respectively. Cross-reactivity of canine LH (LER 16851; Dr. L.E. Reichert, Albany Medical College, NY, USA) with the first mouse anti-rat FSH monoclonal antibodies bound to the tube was determined by adding the preparation to PBS buffer containing $0.29 \%(\mathrm{w} / \mathrm{v})$ human immunoglobulin (Central Laboratory of the Netherlands Red Cross Blood Transfusion Service, Amsterdam, The Netherlands) and $0.36 \%(\mathrm{w} / \mathrm{v})$ bovine serum albumin (BSA; Povite, Organon, Oss, The Netherlands) at $\mathrm{pH}$ of 7.4. Maximal binding in the FSH IRMA was $36.8 \pm 2.2 \%$. At $50 \%$ of the maximal binding the cross-reactivity of canine LH (LER 1685-1) in this assay was $1.8 \%$. The limit of quantitation of canine FSH was arbitrarily defined as the value of the lowest standard, $1.50 \mu \mathrm{g} / \mathrm{L}$, and FSH values below this were arbitrarily assigned the value of one-third of this limit, i.e., $0.5 \mu \mathrm{g} / \mathrm{L}$.

Plasma LH concentration was measured by a heterologous RIA as described previously [4,21]. Briefly, a rabbit antiserum raised against ovine $\mathrm{LH}$ (CSU-204, kindly supplied by G.D. Niswender, Colorado State University, CO, USA), radioiodinated bLH7981 as prepared for our bovine LH assay [22], and canine pituitary standard LER 1685-1 (a gift from Dr. L.E. Reichert) were used in this assay. The intra-assay and interassay $\mathrm{CV}$ for values above $0.5 \mu \mathrm{g} / \mathrm{L}$ were 2.3 and $10.5 \%$, respectively, and the limit of quantitation was $0.3 \mu \mathrm{g} / \mathrm{L}$.

Plasma progesterone concentration was measured by a previously validated ${ }^{125}$ I RIA [23]. The intra-assay and interassay CV were 6 and $10.8 \%$, respectively, and the limit of quantitation was $0.13 \mathrm{nmol} / \mathrm{L}$.

Table 1

Accuracy and precision in the estimation of follicle stimulating hormone (FSH) by immunoradiometric assay

\begin{tabular}{|c|c|c|c|c|c|}
\hline Dilution & Added dose $(\mu \mathrm{g} / \mathrm{L})^{\mathrm{a}}$ & Estimated dose $(\mu \mathrm{g} / \mathrm{L})^{\mathrm{b}}$ & S.D. $(\mu \mathrm{g} / \mathrm{L})^{\mathrm{c}}$ & C.V. $(\%)^{\mathrm{d}}$ & Recovery $(\%)^{\mathrm{e}}$ \\
\hline Undiluted & 47.76 & 47.76 & 0.99 & 2.07 & 100 \\
\hline $1: 2$ & 23.88 & 22.25 & 0.95 & 4.26 & 93.2 \\
\hline $1: 4$ & 11.94 & 10.59 & 0.41 & 3.88 & 88.7 \\
\hline $1: 8$ & 5.97 & 5.24 & 0.31 & 5.90 & 87.8 \\
\hline $1: 16$ & 2.98 & 2.65 & 0.13 & 4.95 & 88.9 \\
\hline $1: 32$ & 1.49 & 1.32 & 0.13 & 9.88 & 88.6 \\
\hline
\end{tabular}

Each dilution was measured six times. All samples were measured in the same assay.

${ }^{\text {a }}$ Canine FSH was added by diluting plasma collected from an ovariectomized bitch 10 min after intravenous administration of a GnRH analogue $(10 \mu \mathrm{g} / \mathrm{kg})$ with plasma from an anestrous bitch.

${ }^{\mathrm{b}}$ Values were corrected for the FSH responses in the IRMA of $1.57 \mu \mathrm{g} / \mathrm{L}$ of the plasma of the anestrous bitch.

${ }^{c}$ S.D.: Standard deviation.

${ }^{d}$ C.V.: Coefficient of variation, this value indicates the precision of the assay.

e Accuracy (recovery) is defined as estimated dose relative to added dose $(E / A \times 100 \%)$. 


\subsection{Data analysis of the plasma profiles}

A Kolmogorov Smirnov test showed that, even after transformation to natural logarithms, the plasma profile data were not normally distributed. Hence the untransformed plasma profile data for FSH and LH were compared per group by the nonparametric Friedman test, followed by a multiple comparisons test using Dunnett's procedure. This test evaluated the changes in the GnRH stimulation test compared with the mean of the two pretreatment values. Differences in the pretreatment values, the peak concentration, the relative peak compared with the pretreatment value (i.e., peak value/basal value) and the area under the curve (AUC) above the pretreatment concentration between the two groups were assessed for statistical significance by the nonparametric Wilcoxon-Mann-Whitney test. The AUC of the hormone concentrations after the GnRH challenge test was calculated by the trapezoidal method after subtraction of the mean pretreatment level per dog. Results are presented as median and range or mean \pm S.E.M. The level of significance was $P<0.05$.

\subsection{Ethics of experimentation}

This study was approved by the Ethical Committee of the Faculty of Veterinary Medicine, Utrecht University.

\section{Results}

The basal (pre-GnRH) plasma concentrations of FSH and LH were significantly higher in the OVX dogs than in the anestrous dogs (Table 2). In the anestrous dogs, plasma concentrations of both FSH and $\mathrm{LH}$ increased after GnRH administration. The plasma FSH concentration was significantly elevated at 10,20 , and $30 \mathrm{~min}$, whereas the plasma LH concentration was significantly higher than the basal level at 10 and 20 min (Fig. 1). In the anestrous dogs, GnRH-induced plasma profiles of both FSH and $\mathrm{LH}$ were characterized by an abrupt and rapid rise followed by a slow decline; slower for FSH than for LH. The GnRHinduced increase in plasma LH concentration above basal levels was much higher than that of FSH. In the OVX bitches, plasma FSH concentration remained unchanged after GnRH administration. In contrast,

Table 2

Characteristics of the GnRH-induced surges of follicle stimulating hormone (FSH) and luteinizing hormone (LH) in four anestrous and four ovariectomized (OVX) bitches (median and range)

\begin{tabular}{|c|c|c|}
\hline & Anestrous bitches $(n=4)$ & Ovariectomized bitches $(n=4)$ \\
\hline FSH pre-GnRH concentration $(\mu \mathrm{g} / \mathrm{L})$ & $\begin{array}{l}5.6^{\mathrm{a}} \\
2.8-13.9\end{array}$ & $\begin{array}{l}81.7^{\mathrm{a}} \\
40.7-107.5\end{array}$ \\
\hline FSH peak amplitude $(\mu \mathrm{g} / \mathrm{L})$ & $\begin{array}{l}25.4 \\
18.4-27.0\end{array}$ & - \\
\hline FSH peak amplitude relative to basal & $\begin{array}{l}3.9 \\
2.0-9.5\end{array}$ & - \\
\hline FSH time of peak amplitude (min) & $\begin{array}{l}20 \\
10-20\end{array}$ & - \\
\hline FSH AUC above baseline ( $\mu \mathrm{g} \min / \mathrm{L})$ & $\begin{array}{l}1475 \\
333-1952\end{array}$ & - \\
\hline LH pre-GnRH concentration $(\mu \mathrm{g} / \mathrm{L})$ & $\begin{array}{l}1.02^{\mathrm{a}} \\
0.81-5.4\end{array}$ & $\begin{array}{l}31.4^{\mathrm{a}} \\
6.4-64.3\end{array}$ \\
\hline LH peak amplitude $(\mu \mathrm{g} / \mathrm{L})$ & $\begin{array}{l}34.9^{\mathrm{a}} \\
26.5-38.4\end{array}$ & $\begin{array}{l}60.7^{\mathrm{a}} \\
48.3-359\end{array}$ \\
\hline LH peak amplitude relative to basal & $\begin{array}{l}30.7^{\mathrm{a}} \\
9.7-41.4\end{array}$ & $\begin{array}{l}3.8^{\mathrm{a}} \\
1.3-6.4\end{array}$ \\
\hline LH time of peak amplitude (min) & $\begin{array}{l}10 \\
10-10\end{array}$ & $\begin{array}{l}10 \\
10-10\end{array}$ \\
\hline LH AUC above baseline ( $\mu \mathrm{g} \mathrm{min} / \mathrm{L})$ & $\begin{array}{l}1038 \\
862-1237\end{array}$ & $\begin{array}{l}2032 \\
688-5546\end{array}$ \\
\hline
\end{tabular}

\footnotetext{
${ }^{a}$ Indicates significant difference between anestrous and OVX dogs.
} 


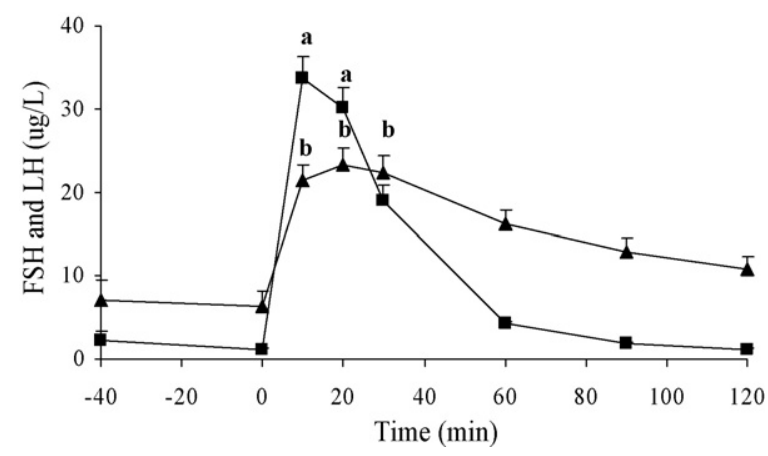

Fig. 1. Mean ( \pm S.E.M.) plasma concentrations of follicle stimulating hormone (FSH) and luteinizing hormone (LH) in four intact anestrous bitches after administration of synthetic gonadotropin releasing hormone $(\mathrm{GnRH})(10 \mu \mathrm{g} / \mathrm{kg})$ via the cephalic vein at $t=0 \mathrm{~min}$. ( $\boldsymbol{\Delta}) \mathrm{FSH}$, (ם) LH. The letters (a and b) indicate significant difference compared with the mean of the pre-GnRH values for the plasma concentrations of LH and FSH, respectively. The bars indicating the S.E.M. are shown only when they exceed the size of the symbols.

plasma LH concentration was significantly increased at 10 and $20 \mathrm{~min}$ (Fig. 2). The median peak concentration of LH was significantly higher in the OVX dogs than in the anestrous dogs, but the relative increase in LH was significantly greater in the anestrous dogs than in the OVX dogs. The median AUC of the LH response did not differ between the anestrous and the OVX dogs (Table 2). The maximal GnRH-induced plasma FSH concentration in the anestrous bitches did not exceed the lowest plasma FSH concentration in the OVX bitches, whereas the GnRH-induced plasma LH concentrations in the anestrous bitches overlapped with the basal plasma LH concentrations in the OVX bitches (Table 2).

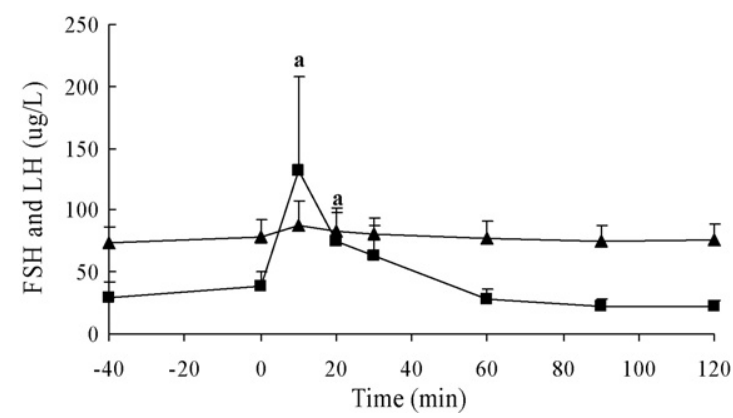

Fig. 2. Mean ( \pm S.E.M.) plasma concentrations of follicle stimulating hormone (FSH) and luteinizing hormone ( $\mathrm{LH})$ in four ovariectomized bitches after administration of synthetic gonadotropin releasing hormone (GnRH) $(10 \mu \mathrm{g} / \mathrm{kg})$ via the cephalic vein at $t=0 \mathrm{~min}$. ( $\boldsymbol{\Delta}) \mathrm{FSH}$, (ם) LH. Letter (a) indicates significant difference compared with the mean of the pre-GnRH values for the plasma LH concentration. The bars indicating the S.E.M. are shown only when they exceed the size of the symbols.

\section{Discussion}

Pituitary gonadotropin release plays a central role in the development and function of the canine reproductive system. The measurement of plasma LH and FSH concentrations before and after the administration of a $\mathrm{GnRH}$ analogue permits assessment of the capacity of the pituitary to secrete gonadotropins under different reproductive conditions. In agreement with the findings of others, GnRH administration elicited a distinct release of LH [4,7-10] and FSH [10]. The course of the GnRH-induced surges in FSH and LH in the anestrous bitches was comparable to what has been reported previously for spontaneous FSH and LH pulses in anestrous bitches [1]. The GnRH-induced plasma LH increments above the pre-GnRH levels were much greater than the corresponding FSH increments. Subsequently, plasma FSH concentration declined more slowly than plasma LH concentration in the anestrous bitches. As in other mammals [24], this may be explained by a different pattern of glycosylation of FSH and $\mathrm{LH}$, resulting in a longer half-life for FSH than LH.

The loss of ovarian feedback after ovariectomy resulted in increased plasma concentrations of FSH and LH in all OVX bitches, as has been reported earlier [1116]. In the OVX bitches, GnRH only elicited a significant response in the plasma LH concentration. Since there was no significant rise in plasma FSH, it can be concluded that the pituitary response to GnRH in OVX bitches differs from that in anestrous bitches. It may be hypothesized that this is the consequence of different intracellular mechanisms for storage and release for FSH and $\mathrm{LH}$. This view is supported by in vitro studies with cells of other mammalian species, which have shown that although FSH and LH are produced in the same cell type, they are stored in different secretory granules [25], newly synthesized FSH is secreted at a greater rate than LH [26], and that the magnitude of the FSH response to secretagogues is smaller than that of LH [26,27].

Occasionally, it can be difficult to verify the neuter status of dogs with an unknown reproductive status [7]. Although all pre-GnRH plasma LH concentrations were higher in OVX dogs than in sexually intact dogs, measurement of circulating LH concentration in a single sample has limited potential for distinguishing between OVX and sexually intact bitches. Taking into account the strong pulsatile nature of LH release [1,13], an overlap in the plasma LH concentration between larger groups of intact and OVX bitches may be expected. Indeed, in the current study GnRH-induced LH increments in the intact bitches overlapped pre-GnRH plasma LH concentrations 
in the OVX bitches. A single high LH value measured by a commercial test kit was not reliable in indicating whether a bitch was intact [15]. In contrast, the results reported here indicate that measurement of plasma FSH concentration in a single sample may well prove reliable for determination of neuter status. Even after GnRH administration the maximum plasma FSH level in the intact bitches did not exceed the lowest plasma FSH level during the entire GnRH-stimulation test in the OVX bitches. Other investigators have also suggested that the pituitary capacity to secrete FSH in the absence of ovarian negative feedback is far greater than that ever observed in the intact bitch $[12,13]$. Such a difference could be expected if there is a specific inhibition of FSH as opposed to LH secretion in intact bitches, i.e., due to ovarian derived inhibin [28]. Furthermore, plasma FSH levels in women usually increase more than do LH levels when the ovaries are functionally inactive or surgically removed [29,30]. This indicates that differences in circulating FSH concentration between intact and OVX bitches could be greater than within-group variability. Another study with a greater number of animals is needed to evaluate the measurement of plasma FSH concentration as a potential diagnostic marker of neuter status.

In conclusion, the results of the present study indicate that in anestrous bitches GnRH challenge results in increased plasma levels of both FSH and LH, whereas in the OVX bitches, in which the basal plasma FSH and LH concentrations are higher, only a rise in the plasma LH concentration is present after $\mathrm{GnRH}$ stimulation. The results also suggest that a test to measure plasma concentration of FSH in single samples appears to have potential in verification of neuter status in bitches.

\section{Acknowledgments}

The authors thank Mr. H.G.H. van Engelen for his assistance in performing the experiments. The excellent assistance of Mrs. D.M. Blankenstein and Ms. C.H.Y Oei of the Biochemical Laboratory is highly appreciated. The critical reading of the manuscript by Prof. Dr. J. Rothuizen and Dr. B.E. Belshaw is highly appreciated. We thank Dr. W.E. van den Brom for his valuable assistance with the statistical analysis and Beckman Coulter BV (Mijdrecht, The Netherlands) for support with the FSH IRMA.

\section{References}

[1] Kooistra HS, Okkens AC, Bevers MM, Popp-Snijders C, Van Haaften B, Dieleman SJ, et al. Concurrent pulsatile secretion of luteinizing hormone and follicle-stimulating hormone during different phases of the oestrous cycle and anoestrus in Beagle bitches. Biol Reprod 1999;60:65-71.

[2] Klein R, Schams D, Failling K, Hoffmann B. Investigations on the re-establishment of the positive feedback of oestradiol during anoestrus in the bitch. Reprod Dom Anim 2003;38:13-20.

[3] Tani H, Inaba T, Tamada H, Sawada T, Mori J, Torii R. Increasing gonadotropin-releasing hormone release by perifused hypothalamus from early to late anestrus in the Beagle bitch. Neurosci Lett 1996;207:1-4.

[4] Van Haaften B, Bevers MM, Van den Brom WE, Okkens AC, Van Sluijs FJ, Willemse AH, et al. Increasing sensitivity of the pituitary to GnRH from early to late anoestrus in the Beagle bitch. J Reprod Fertil 1994;101:221-5.

[5] De Gier J, Kooistra HS, Djajadiningrat-Laanen SC, Dieleman SJ, Okkens AC. Temporal relations between plasma concentrations of luteinizing hormone, follicle-stimulating hormone, estradiol$17 \beta$, progesterone, prolactin, and $\alpha$-melanocyte-stimulating hormone during the follicular, ovulatory, and early luteal phase in the bitch. Theriogenology 2006;65:1346-59.

[6] Speroff L, Fritz MA. Neuroendocrinology. In: Clinical gynecologic endocrinology and infertility. Philadelphia, PA, USA: Lippincott Williams and Wilkins; 2005. p. 145-85.

[7] Buijtels JJCWM, Beijerink NJ, Kooistra HS, Dieleman SJ, Okkens AC. Effects of gonadotrophin releasing hormone administration on the pituitary-ovarian axis in anoestrous vs ovariectomized bitches. Reprod Dom Anim 2006;41:555-61.

[8] Chakraborty PK, Fletcher WS. Responsiveness of anoestrous Labrador bitches to GnRH. Proc Soc Exp Biol Med 1977;154: $125-6$.

[9] Jeffcoate IA. Concentrations of luteinizing hormone and oestradiol in plasma and response to injection of gonadotrophinreleasing hormone analogue at selected stages of anoestrus in domestic bitches. J Reprod Fertil 1992;94:423-9.

[10] Reimers TJ, Phemister RD, Niswender GD. Radioimmunological measurement of follicle stimulating hormone and prolactin in the dog. Biol Reprod 1978;19:673-9.

[11] Chaffaux S, Chassagnite F, Thibier M. Concentration of LH après stimulation par la gonadoliberine (LRH) chez la chienne et effet de l'ovariectomie. Rec Med Vet 1981;10:725-33.

[12] Olson PN, Mulnix JA, Nett TM. Concentrations of luteinizing hormone and follicle-stimulating hormone in the serum of sexually intact and neutered dogs. Am J Vet Res 1992;53: 762-6.

[13] Concannon PW. Biology of gonadotrophin secretion in adult and prepubertal female dogs. J Reprod Fertil 1993;47(Suppl):3-27.

[14] Jeffcoate IA. Gonadotrophin-releasing hormone challenge to test for the presence of ovaries in the bitch. J Reprod Fertil 1993;47(Suppl):536-8.

[15] Löfstedt RM, Vanleeuwen JA. Evaluation of a commercially available luteinizing hormone test for its ability to distinguish between ovariectomized and sexually intact bitches. J Am Vet Med Assoc 2002;220:1331-5.

[16] Reichler IM, Pfeiffer E, Piché CA, Jöchle W, Roos M, Hubler M, et al. Changes in plasma gonadotropin concentrations and urethral closure pressure in the bitch during the 12 months following ovariectomy. Theriogenology 2004;62:1391-402.

[17] Concannon PW, Hansel W, McKentee K. Changes in LH, progesterone and sexual behavior associated with preovulatory luteinization in the bitch. Biol Reprod 1977;17:604-13.

[18] Wildt DE, Panko WB, Chakraborty PK, Seager SWJ. Relationship of serum estrone, estradiol-17 $\beta$ and progesterone to $\mathrm{LH}$, 
sexual behavior and time of ovulation in the bitch. Biol Reprod 1979;20:648-58.

[19] Okkens AC, Bevers MM, Dieleman SJ, Willemse AH. Shortening of the interestrous interval and lifespan of the corpus luteum of the cyclic dog by bromocriptine treatment. Vet Quart 1985;7:173-6.

[20] Okkens AC, Dieleman SJ, Bevers MM, Willemse AH. Evidence for the non-involvement of the uterus in the lifespan of the corpus luteum in the cyclic dog. Vet Quart 1985;7:169-73.

[21] Nett TM, Akbar AM, Phemister RD, Holst PA, Reichert Jr LE, Niswender GD. Levels of luteinizing hormone, estradiol and progesterone in serum during the estrous cycle and pregnancy in the Beagle bitch. Proc Soc Exp Biol Med 1975;148: 134-9.

[22] Dieleman SJ, Bevers MM. Effects of monoclonal antibody against PMSG administered shortly after the preovulatory LH surge on time and number of ovulations in PMSG/PG-treated cows. J Reprod Fertil 1987;81:533-42.

[23] Okkens AC, Teunissen JM, Van Osch W, Van Den Brom WE, Dieleman SJ, Kooistra HS. Influence of litter size and breed on the duration of gestation in dogs. J Reprod Fertil 2001;57(Suppl): 193-7.
[24] Schwartz NB. The 1994 Stevenson Award Lecture. Folliclestimulating hormone an luteinizing hormone: a tale of two gonadotrophins. Can J Physiol Pharmacol 1995;73:675-84.

[25] Moyle WR, Campbell RK. Gonadotropins. In: Adashi EY, Rock JA, Rosenwaks Z, editors. Reproductive endocrinology, surgery and technology. Philadelphia, PA, USA: Lippincott-Raven Publishers; 1995. p. 683-724.

[26] Chowdhury M, Steinberger E. Biosynthesis of gonadotrophins by rat pituitaries in vitro. J Endocrinol 1975;66:369-74.

[27] Muyan M, Ryzmkiewicz DM, Boime I. Secretion of lutropin and follitropin from transfected $\mathrm{GH}_{3}$ cells: evidence for separate secretory pathways. Mol Endocrinol 1994;8:1789-97.

[28] Shupnik MA. Gonadal hormone feedback on pituitary gonadotropin genes. Trends Endocrinol Metab 1996;7:272-6.

[29] Bulun SE, Adashi EY. The physiology and pathology of the female reproductive axis. In: Larsen PR, Kronenberg HM, Melmed S, Polonsky KS, editors. Williams textbook of endocrinology. 10th ed., Philadelphia, PA, USA: Saunders; 2003. p. 587-664.

[30] Genuth SM. The hypothalamus and pituitary gland. In: Berne RM, Levy MN, Koeppen BM, Stanton BA, editors. Physiology. 5th ed., St. Louis, MO, USA: Mosby; 2004. p. 819-59. 